\title{
Dynamics in language
}

\author{
Valentin Dragoș Biro* \\ Doctoral School of Philological Studies, "Alexandru Ioan Cuza” University, Bd. Carol I 11, 700506 Iași, Romania \\ "Spiru Haret" Pedagogical National College, Bd. Spiru Haret 6, 120260 Buzău, Romania
}

Article info

History:

Received April 7, 2019

Accepted April 16, 2019

Published May 7, 2019

Key words:

evolution

Darwinism

language

diachrony

linguistics

\begin{abstract}
Language is subjected to a double definition process: by the static reality characteristic of the system, due to inertia to change, and by its permanent character regarding the language acts producing, through speaking. Because it is under the pressure of concrete communicative needs, a language is subjected to a continuous dynamics assuring the language progress or regress, both aspects, together with neutral modifications, actually meaning, in the Darwinist perspective, the language evolution. The article, thus, comes with a necessary conceptual delimitation between the language evolution and progress, on the one hand, but also between causes which determine the evolution and the evolution in itself, as a process.

Linguistics has faced radically different approaches on its topic of study, natural human language; the perspectives on language differ from the relationships network which make the elements creating one language or another to get the quality of systems, to a product of man's will and freedom, because the language cannot be separated from the speakers' freedom, or to the attention paid to meanings, these being always socially constituted, based on the interactions between a community members. In such a diversity where divergence dominates convergence, this article intends, in subsidiary, to fix, from an diachronic perspective, the definition of linguistics as being, in fact, the history of evolutions the language has met since its beginnings.
\end{abstract}

\section{Introduction}

\subsection{Language - topic of study}

Linguistics is traditionally perceived as exclusively representing the scientific study of human natural language. Trying to define itself as being an autonomous science and wishing to follow the requests considered rightful for being an autonomous science (to find, to individualize and to define the topic of study; if the investigation object comes into the sphere of concern of other science, to identify the specific aspects of the object), linguistics has known different approaches to its topic of study, human natural language, taking into consideration that, in Saussurian way, the point of view on the topic is the one that created, although it still accepts the fact that the topic pre-exists to the science studying it. Generally accepted is yet the perspective according to which linguistics is a science belonging to human social sciences due to the fact that "it defines itself by reporting to those essential characteristics belonging to human being: capability of getting knowledge, capacity of expressing this knowledge and ability to transmit it to the fellows" (Milică \& Moisuc, in Notă asupra ediției of Irimia, 2011).

Thus, ever since Antiquity until the last century, the language had been considered an instrument of thinking, of reason (which it had been identified with), means of knowing a reality seen as being unique, static and objective and reflected in language through thinking. Then, the language was seen through its quality as collective communication instrument, inter human, so

*Email address: valibiro@yahoo.com. 
a social fact or even a social institution, a supra -individual good and independent of subjective intrusion of community members independently perceived. To this formalist perception is to be later added the structuralist one, which tries to extract from the language mostly the relationships network which make the elements creating one language or another to get the quality of systems thus turning, to a certain degree, a defining characteristic into an exclusive one.

We also have to mention here the behavioral conception (human natural language and the languages it materializes in, represent only a way of being, a conduct, the most typical behavior of human body), the naturalist conception (biological, organicist, the language being seen as a living organism, totally independent either of individual or society, subjected to the same fatal rules of nature: growing up, improvement, regress, disappearance) and psychologist conception (language is no longer seen as a causally determined phenomenon either by thinking or natural laws, but as an independent product of human psychic ${ }^{1}$; language is no longer a product of necessity, an imposing deriving from the man's social being quality, but a product of freedom and human will, in the sense in which, if abstract language depends on norm, real language, concrete one, cannot be separated from speakers' freedom.

Frequently used is also the sociologic conception: any language is a codification system, and in order to exist communication and social interactions, the actors in the process of communication need to have the same codes system or, in other words, to use the same types of meanings; this thing is possible only based on some social relationships, relatively settled at community level where the respective language can be found; this condition is universal and applicable to any type of language, the meanings being always socially built; the meanings impose themselves, keep themselves and change in time based only on the interactions between the members of a community.

From the diversity of the views expressed, I focus on a definition of linguistics from evolutionary perspective: "On a general level, if people have understood that the whole biology is nothing but the history of the differences that organisms of the same type have suffered by adapting to different environment, we can say that linguistics is nothing but the history of evolutions, different regarding people and places through which the primitive model being passed" (Darmesteter, 2015).

\subsection{Language - perspectives}

Related and by no means separable are the perspectives of which any science can be looked at, perspectives which are, in their turn, in a logical and provable interdependence: (a) the synchronic perspectivedescribing any aspect of a science subject, topic of study, by what it represents in itself, statically; (b) the diachronic perspective-which presents any aspects of a science, subject, topic of study by reporting to its evolution in time, dynamically.

The description (synchronic perspective) and history (diachronic perspective) do not exclude themselves from the topic of study point of view, are not antithetic or contradictory, but complementary.

Related to the linguistics field (as a science), there have been many opinions referring to the need of turning into complementarity of synchronic-diachronic dichotomy, exemplified here without the claim of exhaustive approach specific to a meta-study:

"Knowledge, therefore, is reached only after understanding the fact that the accurate description of element and state use only if, after having seen as separate parts for a moment, are perceived in their unitary becoming. Because neither the structure or the function exists per se outside the whole they create and serve, together and equally, in order to properly understand, the observation of the state must be followed by the entity processes' examination-within the extended

\footnotetext{
${ }^{1}$ Wihelm von Humboldt defined language as being a creative, free reality, certainly not a product given and taken per se (in
} Über die Verschiedenheit des menschlichen Sprachbaues und ibren Einfluss auf die geistige Entwicklung des Menschensgeschlechts). 
context of its existence. Such an inclusion is acquired by examining the material which is the base of the whole research repeatedly alternating the microscopic analysis with telescopic synthesis, where the perspectives' axis (synchronic, belonging to the state, and diachronic, belonging to the processes) interferes to the methods' one (inductive, belonging to particular-concrete certainties, and deductive, belonging to universal-abstract suggestions)” (Gafton \& Gafton, 2016, p. 9);

"The relationship between the synchronic and diachronic aspect of language is dialectic, a characteristic which was not ignored by Saussure as some post saussurien linguists would allow people to understand" (Irimia, 1978, p. 255);

"Lately there has been noticed the need to soften the rigidity regarding the saussurien dichotomies. Some people rightly said that the gap dug by Saussure between langue and parole had to be filled. And, as far as language is concerned, they insisted on the necessity of filling the gap between synchrony and diachrony, which was really necessary. [...] We must not forget that the antinomies settled by Saussure have been explicitly rejected by a whole series of studies." (Coșeriu, 1997, p. 14). The example used in Synchrony, diachrony, history is the one of H. Schuchardt who, in a review to Saussure's Course (Hugo Schuchard-Brevier, Halle, 1928, p. 330), used to write about the separation between synchronic and diachronic linguistics: "This seems to me as if we dissociated learning about coordinates into one about ordinates and into another one about abscissas. In language, as well as generally speaking, the rest and the movement (the latter one being widely considered) do not form an opposition [...]".

„[...] Even since 1870, speaking about the language system, Baudouin De Courtenay found in it not only the correlations between the synchronic elements but also the fact they represent the result of anterior evolution and, at the same time, the base of later development: «The language mechanism and generally its structure and elements in a certain moment represent the result of the whole history before it, of the whole evolution and, reversely, this mechanism in a certain moment conditions the later evolution of language. [...]» And, finally: «There is no rest in language... in language as well as in nature everything lives, everything moves, everything transforms. The quiet, the stop, the stagnation are apparent phenomena, they represent a particular case of moving within a minimal modification. The language statics is only a particular case of dynamics or, better said, of its kinematics.»” (G. Mihăilă, Raportul dintre sincronie și diacronie, in Graur et al., 1971, p. 359).

And the examples can be more, of course.

To sum up, the dynamics of language, the permanent becoming of linguistic culture which can be seen in the continuous production of texts, on the one hand, and the cultural variations, on the other hand, generate both a synchronic and diachronic approach.

\section{Language - system and structure}

The alternatively synchronic and diachronic approach is imposed by the fine $\operatorname{limit}^{2}$ separating the notions of system and structure regarding the inner organization of language. The system is the ensemble of linguistic signs and the relationships between them. The differentiation and opposition define the linguistic sign : every sign exists because it is a part of a system and has an identity because it opposes other signs. The structure is configured by the ensemble of relationships which they develop and hypothetically linguistic signs can develop. Practically, the structure represents the system's way of being and working. Both of them define themselves in correlation with the linguistic sign, which, within the system, defines its

\footnotetext{
2"The relation between language system and structure is indissoluble until they are confused. Many times, the two terms have been and still are interpreted in synonymy (at Humboldt) or one instead of the other (more frequent, lately structure instead of system: at Piaget and others)" (Irimia, 1978).
} 
identity by the position it takes in different series of paradigmatic oppositions: „The structure determines and emphasizes the value of linguistic signs which materializes in type of significant and functional units, which a statement is organized in. As the distinction between system - structure is possible only within interpretation, although it is real in the same way either identity or value cannot be differenced within the objective reality of language" (Irimia, 1978).

The linguistic sign is in the same time oriented towards the objects' world ${ }^{3}$ and towards the semiotic system of the language it belongs to ${ }^{4}$. The user perceives both orientations within their own conscience in the transmitting and receiving process, namely a continuous and direct utilization of language. The relation between signified and significant supposes, in its concrete accomplishment, the intersection of syntagmatic relationships with the paradigmatic ones. The intersection of the two axes reflect the tight reports between system and structure, on the one hand, and between language of speaking in the real linguistic act within which the signification process is accomplished, on the other hand. Paradigmatically speaking, the signs are invested with a virtual value in guiding the signification process according to the signs classes and categories they are grouped into; from a syntagmatic view the virtual variety is replaced by a concrete choice. The sign signification is thus a result of the influence of signs nearby and of the influence of signs which could have appeared or not instead of the present one.

We have already noticed that the perspectives on language differ in time, from the connections network which makes the elements composing one language or another to get the quality of systems, to the product of human will and freedom in the sense that the real, concrete, language cannot be separated from the speakers' freedom, or to the attention paid to meanings, the latter ones being only socially constructed because they impose themselves, keep themselves and change themselves only based on interactions between the members of a community. Far from excluding themselves, these approaches actually represent faces of the same reality ${ }^{5}$ which is the language and which reveals itself through language. Thus, in a paradigmatic way, the language is defined as a system that uses a virtual variety of signs in relation, so that, in a syntagmatic plan, the signs created in the system gain concrete meaning through the free, willful, conscious choice of the speakers, a choice based on previous interaction with members of a community stable linguistically.

Accepting the existence of the two plans, it becomes impossible to perceive the language as a selfsufficient, static and indifferent reality ${ }^{6}$ to extralinguistic conditioning, although there have been approaches in this respect ${ }^{7}$. Thus, language is subjected to a double definition process: on the one hand,

${ }^{3}$ Within the language - thinking relation.

${ }^{4}$ Within the language - society relation.

${ }^{5}$ The science cannot be separated from its topic, from its topical research - the reality containing countless faces, so that different sciences deal with revealing the reality from different point of views. On the other hand, the reality, although it is very diverse in manifestation, has unitary character and, as a result, can be deeply perceived, as much as possible, only if we bet on a sciences' syncretism, because the optimal working of an organism both in every moment of its existence considered separately and in its uninterrupted and fluent existence do not result from the separate activity of the cells composing it but from their cohesion (apud Gafton \& Gafton, 2016).

${ }^{6}$ During the history of linguistics the approaches on the role, object, methods have evolved since the temptation of selfsearching for all of the answers, the language being conceived as a separate part from the reality whose part it was, getting "the autarchic autonomy complex", to "the alluring thought that language is a system of signs totally ruled by inner laws" (Gafton \& Gafton, 2016).

${ }^{7}$ Rejected unquestionably in the scientific community: "As you can see, the approach from the synchronic perspective could offer detailed analyses, thinking that it found in texts what is not to be found there and not being able to find out what is to be found there. It would wrongly interpret forms, functions, and meanings, and it would lose exactly what gives importance to that text-within linguistic research and in general. The offered image would correspond to a deductive scheme or to an extrapolated mental construct, meaning to some projections and conjectures, but the only necessary thing would be missing: the indispensable fundamentals offered by the research reality connected to the hyper-ordinated reality and which is able to offer valid scientific results. After the diachronic perspective settles general and particular features of the whole context, the procedural route generating the text, the evolutionary results of the Romanian language, its contact results with influential factors, the peculiarities of priming and edification for the old Romanian literary aspect, the synchronic perspective can have an efficient action, within an alternative conjugated process, of both perspectives. This happens because no other entity statically regarded at and taken out from the organism whose part it is cannot generate knowledge, not even about itself because, decon- 
having the characteristic of a static reality system due to its changing inertia and, on the other hand, having the permanent character of producing language acts by speaking.

This permanent production of language acts depends on free-will choices the speaker ${ }^{8}$ makes. In his Course, Saussure underlines the free-will essential role in producing language acts: the basis of distinctions that the significant and signified use in speaking and the source of the meaning later gets is represented by the human natural born capacity of discriminate and dissociate into classes, of making choices and of later using differently those classes: "We do not have to understand the speaker would be completely free to settle their terms and that if they would they could use them differently than heard from others. Of course, there is a certain freedom and it is the base of individual styles. We are compelled to use the words other people know, with the meanings we have learnt" (Graur et al., 1971).

The importance of free-will is emphasized by Tullio de Mauro in the critical study preceding Saussure's Course: "From the free-will, two language antithetic characteristic result". First of all, its mutability during time [...] There thus happens that some far away linguistic traditions start to converge or that the same linguistic tradition to be able to split up into profound divergent idioms. The languages do not face other limits except those only and truly universal (universal, of course, for human species), namely human perceptive and aware apparatus structure and his acoustic and fonator apparatus: within those, the possibilities to reorganize the infinite series of different phonies and meanings of significant and signified are unlimited. In the latest analysis, the free-will numbs the shakes generated by the phonies and meanings' possible changes $[. .$.$] The usage the society gives to the language is the condition for the language to be$ viable [...] Exactly like free-will, the social connection is a stability factor and, at the same time, a changing factor. Due to the fact of being social, it guards the language from individuals' and small groups' whims ${ }^{10}$. On the other hand, the same social nature exposes the language to changes when the need of already existing distinctions minimalizes, or on the contrary, when there appears the need of new distinctions".

It should be noted that that this perspective is also subjected in time to a critical analysis which

textualized, it cannot refer any longer to itself in the context, but to its new, apparent state" (Gafton \& Gafton, 2016). Or: "The opposition thus enrolls in prolonging the first one, the diachronic dimension of language having its starting point in speaking. As well as language and speaking could not be the objects of the same linguistics, due to the heterogeneous character of human language, wholly considered, the synchronic and diachronic dimension cannot be investigated-in Saussure's opinion, by the same linguistics because of the disparate character of the synchronic and diachronic language facts, both by different rules that govern them, by nature and specific way of working, and by specific character of investigation methods [...]. It is true that for the speakers' consciousness the language does not exist in the living act of communication, except in synchrony with them. [...] It is true that the best way to get knowledge about the essence and character of a language is the synchronic analysis of the concrete facts (B. de Courtenay), but to get knowledge about the construction of a linguistic system, the most important is the interpretation of changing which took place in time, along with the respective linguistic community evolution. It is the social phenomenon character of the language that imposes interpretation both of its synchronic and diachronic reality the more so as there are no pure synchronic states and as a result, the description of the system itself from a certain stage imposes the interpretation of some phenomena resulting from coexistence of new forms with the traditional ones" (Irimia, 1978)

${ }^{8}$ I do not exclude from here the essential difference between langue and parole, so that by using the notion of speaker, I mean a user of a linguistic system in the process of producing new text. I will talk about the relationship between speaker free-will later.

${ }^{9}$ Along with opposivity and linearity.

${ }^{10}$ Related to this approach, there comes the legitimate question regarding the way (or criteria) which determine a language fact or another to be included in this category. Mainly, there would be necessary a comparison to what is, linguistically speaking, a habit, the balance state that the language had been tended to until that moment, an accepted and adopted state, in order to notice the alteration degree. Thus, only a state of language would be analyzed, namely an exclusively synchronic approach, a perspective already settled as being desirable due to its limitative character. It is justifiable to turn the binom langue - parole into langue - parole - norm from E. Coseriu's point of view (the norm: system of compulsory accomplishments, established socially and culturally; it... corresponds to what was said and is still said within the considered community; it consists of the already accomplished historically models; it corresponds to the language fixing in traditional patterns, etc). On the other hand, even a whim represents a language fact, with real manifestation at a certain time, so, using the Saussure's point of view, the only unique linguistic reality for the respective individuals or for the respective small groups. For those, who are incapable to place their own defining features regarding the use of language in the communication historic process, these whims represent the linguistic culture defining them in the use of language. 
nuances its delimitations; for example, in Benveniste (1966) is considered that only the relation between the linguistic sign and an extra-linguistic reality can be defined as arbitrary.

\section{Dynamics in language}

Regarding the report between speaker and language, yet the linguistic sign is almost absolutely nonarbitrary. The speaker ${ }^{11}$, except some limits which deal with stylistic usage of language, is not free either to change the report between a linguistic sign and the settled reality, or to modify on their will, the significant' and signified' structure. As long as the speakers' freedom of choice is (almost total) on the one hand, but (totally) limited on the other hand, there is to be imposed the factors' ensemble identification which determines the existing of a language, in one form or another, at a certain given moment (from synchronic perspective) or in different moments of manifestation (from diachronic perspective).

The history of a language (the history of its construction as a distinct semiotic system and its becoming to a synchronic stage known to the speaking subject) knows two important stages: (a) the formation of its own system, by destroying and then developing a specific language base - system; (b) the system evolution by permanent passes from one balance to another, towards its desire to reach a maximum degree of stability and regularity. The process takes places within langue - parole relation, characterized by a permanent state of tension between the need of adaptation to communication needs, always changing (while forming its own system, radically changing), and the exigencies imposed by the language functionality for the whole community. The norm is especially ignored or sometimes fully rejected, and the generalization of abandoning the norm leads, while forming its own system, to the destruction of the old systems' balance and to the forming of a new balance.

The factors which condition the forming of the new linguistic system and, after that, the uninterrupted process of its diachronic, namely that of its real existence, are multiple. Some of them are extra-linguistic, others are linguistică ${ }^{12}$, some derive from others or enter into conflict with them, but all of them act, especially togheter, in tight connection with the language communication function which permanently imposes new exigencies. Between the two series of causes, external and internal, actually occur complex relationships, from implication to position, whose nature changes regarding the historic stage of language. During the forming of the new system, the external cause have an active role, extremely emphasized. Subsequent, the system gains a relative autonomy towards them and the active role it is taken by the inner causes, which act in the sense of system regulation and a balance settlement. But, beyond this relevance changing, the mixture of the inner causes with the external ones is permanent, resulting from the language communication function itself, from its character of social phenomenon, from its usage by the speaking subject who always positions the linguistic act between language and speaking ${ }^{13}$.

The extra-linguistic factors (the origin and history of a nation, the level of development of spiritual civilization, the ethnic character, the economic, social, cultural, political development of the social-linguistic community) represent the general frame in which a language is constituted.

\footnotetext{
${ }^{11}$ Found, through norm, between language (all the given possibilities and freedoms) and speaking (all the possibilities turned into deeds, so the ensemble of taken freedoms).

${ }^{12}$ For Graur et al. (1971), internal and external causes.

${ }^{13}$ From following the factors conditioning, stimulating or even generating changes in language, we can draw a conclusion, previously mentioned by Saussure, S. Puscariu, A. Martinet, Al. Graur and others: there is no cause, either internal or external, which alone or with mandatory, could generate a certain phenomenon. The changes taking place with the structure of linguistic system, and through this, within the system's structure-favored by both the arbitrariness of the internal relationship, between the significant and signified, by the relation between the language and ontological plan, and by the tendency to motivate it-, derive from a complex causality, where a factor can have, at a certain time, a more important role, but its action is correlated to other factors". The language evolution is a result of the system's inner movement (generalized by some directions in the diachronic phonology), of the objective needs of communication and opposition, subjective or objective, of the speaking subject" (Irimia, 1978).
} 
Without a direct interference in the language modification, these factors orient the action of linguistic factors ${ }^{14}$.

The linguistic external factors (contact between languages, bilingualism, the position of the speaking subject or social group to language) come to prolong the extra-linguistic factors, which condition them in their consecutive or simultaneous action: "The most important role in generating some changes is held by the innovations sprung from the speaking subject's creative force, a thing which is characteristic for writers and popular creators. The writers' role becomes especially active in certain periods of a language history, essential for regulating the system, by creating a new precise norm to the profound spirit of the language system, As long as, yet, the innovations remain individual, they are actually not important for the language system, regardless their origin, they do not influence it in any way, but they remain in the speaking sphere. [...] In order to become language facts, while they are spreading, the innovations have to face inertia, conservatory attitude of some age, social categories. Their spread horizontally, on more or less extended territories, is conditioned by their spread vertically, regarding different culture, sex, age categories. By this demand for socialization, the innovation actually imposes itself within the language diachronic, as collective innovation." (Irimia, 1978).

The linguistic inner factors are, actually, some very general principles for synchronously functioning of the language, which impose themselves as laws, more or less imperative, in diachronic: minimal effort, language economy, functional efficiency, paradigm integration, interaction of signs and language units in the system ${ }^{15}$.

Between the external and internal linguistic factors, the reports are of interdependence. The external factors act on the system, because they are caused by extra-linguistic factors, but also because the system itself claims a series of changes regarding the organization of its inner balance. But the inner balance is shaken by external factors actions (but not only). This type of dynamics makes the inner linguistic factors action to be permanently intertwined with the one of the external linguistic factors. The differentiation and opposition define the linguistic sign: every sign exists because it opposes to others. The structure is confirmed by the ensemble of the relationships they develop, or hypothetically are able to develop. Practically, the structure represents the system's way of working and being. Both of them can be defined by reporting to the linguistic sign, which, within the system, defines its identity by opposition it takes in the different series of paradigmatic oppositions.

\footnotetext{
${ }^{14}$ Within the same approach, E. Coseriu considers that these "function, in terms of changing, as selectors: they are conditions and limits of linguistic freedom in its action to create and recreate the language. Among many innovations noticeable in speaking, only some of them can be adopted and spread, because only some of them correspond to the possibilities and needs regarding the functional system or find proper conditions regarding the individual linguistic science. A linguistic change always starts and develops as shifting movement. But, for the norm to move, it is absolutely necessary either this thing to be proper and necessary functionally speaking, or the norm to be unknown, or ignorance of it not to affect the functionality of the language (understanding between speakers). Being a traditional science, the language changes its weak points mostly, namely exactly where the system does not efficiently corresponds to the speakers' communicative and expressive needs; the necessary changes find their limit in the certainty of tradition" (apud Irimia, 1978, p. 124).

${ }^{15}$ The antinomy between the tendency of assimilation the phonemes got into syntagmatic relationships and the conservatory tendency of the paradigmatic relationships is to be balanced by turning the distinctive aspect into a change unit; keeping (or making) the phonemes' maximum difference; the system's organization (the language evolve to a permanently systematic character). It is the antinomy between the tendency to assimilate the near by phonemes in a syntagmatic plan and the tendency towards conservation specific for the paradigmatic plan, the phonetic laws' action is countered by the analogy action. By the sign attraction then, some series of oppositions will be completed, by filling up «the empty boxes». We do not have to understand from here either the system, by its inner force, looks for means «to fill up» all «the empty boxes», or the system could reach, at a certain moment, a perfection stage, when the evolution would cease and the languages could introduce, through borrowing, the missing phenomena. Only linguistic signs are to be borrowed and they adapt to the phonologic and morphologic system of the borrowing language (in this process analogy has a main role). The language economy principle can determine some signs «misfit» maintaining, to create a new balance, by opening the way for developing or extension of a certain phonologic opposition” (Irimia, 1978).
} 
In the paradigmatic plan, the signs are invested with a virtual value, in managing the meaning process, according to the signs' classes and categories they are grouped into; in the syntagmatic plan, the virtual variety is replaced by a concrete choice. Thus, in a paradigmatic plan, the language is to be defined as a system using a virtual reality of related signs, so as, in a syntagmatic plan, the signs in the system gain the concrete meaning by the speakers' free, willing choice, a choice based on the previous interaction with the members of a linguistically stable community.

The arbitrariness has an essential role in generating language acts: at the origin of the distinctions the significant and signified introduced while speaking, and at the origin meaning later gained, there is the human's natural born capacity of discriminate and associate into classes, of making choices, and of later differently using these classes. As far as the report between the speaker and language is concerned, yet, the linguistic sign is almost absolutely non - arbitrary: „The speaker, except some limits which belong to the language stylistic using, is not free either to change the report between a linguistic sign and the named reality, or to change, according to their will the structure of the signified and significant. By arbitrariness ${ }^{16}$ we understand that, in the objects, there are no elements compelling the use of a certain sound complex instead of others ${ }^{17}[\ldots]$ Actually, language was born when the evolving humans, agreed, without a previous convention, on a permanent connection between a sound complex and a meaning, and this thing would happen only there, where the sounds, through their own constitution, suggested the idea which was to be expressed. After the same group of sounds had generated the same reaction, in many circumstances, the human became aware of the fact that, producing certain sounds, they could gain that reaction from the ones listening to them. Then, the man started speaking designedly and soon they felt they needed new words to name notions which had been absent before. So, the human came to intentional create words" (Graur et al., 1971).

It is now to be admitted ${ }^{18}$ that, in general, the causes for the language changes are not easy to identify and it is not obvious the reason why one change actions to the detriment of others, with consequence in the optimization of a language aspect and, simultaneously, in increasing complexity of another one, although in the last years were written down some important works on these aspects, in phonology, morphology, syntax, diachronic semantics. The main competence in the language movement, consists of the permanent tension (and, from here, the balance) between the need of tinted, exact and clear transmission of contents, on the one hand, and the tendency to simplify the form, on the other hand, a reality the average speaker (or whole generation of speakers) is not aware of, and which they do not create for itself. Together with this central competence, social and historic factors, the contact between languages, cultural and geographical factors, writing tradition, the linguistic system itself act by imposing different evolution rhythms, but non affecting essentially the continuity (as long as the changes are gradual within the speakers' community). So that: "There is not spontaneity ruling the language because, thereby, chaos would be generated, and no finality rules either ${ }^{19}$, because, thereby, all modifications are to be made in the sense of progress. Under the pressure of communication needs, more and more complex, a language permanently changes, based on its objective inner laws and the conscious intervention which takes into consideration these laws" (Wald, 2017).

From the above information we can notice that the language, being under a permanent pressure, either

\footnotetext{
${ }^{16}$ Not to be confused with the notion of "groundless".

${ }^{17}$ What is easy to demonstrate, both logically and factually, by proving that every language uses a different term to express the same idea (what is called nămol in Romanian is called schlamm in German, mud in English, iszap or sár in Hungarian, barro in Spanish, kerpiç in Turkish, гpязs (gryaz) in Russian, fango in Italian, etc.), or that in a language the same object can have many names (the Romanian language knows the simultaneous usage of the following words: noroi, glod, tină, nămol, mîl, every of them having its meaning nuances).

${ }^{18}$ Wald (2017, p. 287-311).

${ }^{19}$ As partially considered, for example, E Coseriu.
} 
from inside ${ }^{20}$ or outside ${ }^{21}$, the system, subjected to individual choices and to the social and historic context variation, has been in a permanent dynamic change, ever since its beginnings.

Except some situations when the context imposes the following of some terminological conventions, the change manifests, as an expressive necessity, spontaneously and immediately and not as a deliberate intention of modifying the language seen as an inter-individual communication means. (I have chosen the term "inter-individual" instead of "collective" in order to emphasize the fact that this community, mainly but not exclusively linguistic, represents the sum of individual contributions to the communication act). Thus, we can notice the simultaneous existence of some innovative elements and of some old linguistic elements, not yet replaced. Moreover, the choices are made individually, but they are influenced by the linguistic tradition which is to be found in every person's linguistic culture, and by the social-historic context: a theoretically individual choice on the syntagmatic axis is, in fact, equally, freedom and tradition, culture and linguistic culture, subjectivity and objectivity, denotation and connotation.

\section{Evolution or progress?}

It is obvious the profound dynamically language character, a dynamics existing in the spoken, real language, sometimes settled in texts, unceaselessly shown from the language's beginnings and until now. We can talk about the static character of language only if we analyze language cutouts, aspects showing the certain moments, although specific to an exclusively synchronic approach, or related to the capacity, limited until it becomes zero, of the speakers to realize the individual yet active role they have in the language's existence. But, even in this way, the cutouts represent the photo of a real moment in the speakers' consciousness, in the context of concrete manifestation of communication abilities. We can talk about the static character only relating it to the abstract language.

The language dynamics mainly means change. The language that does not change is the abstract one, which is not under the influence of the previously mentioned external factors; the real language, in its concrete existence, is a permanent process of changing, because it cannot be isolated either by the influence of the external factors or of the inner ones', namely all can be found in the speakers' history and freedom of expression $^{22}$ from a linguistic community. The social facts are not exterior to the individuals, but they are inter-individual, namely they are individual only when they are together with others. The language, above all the other social facts, is not unknown to the individual (meaning, external), it is not imposed to them, but is made by the individual's participation and the individual recognizes it as being themselves' equally as it is others'.

Thus, the change does not belong to the speaking individual but it is not unknown to them. The change is made together with the individual, without their intention to change something. The language means, for an individual, the system used so as they can talk as the others, as part of a linguistic community, speaking act that uses methods and reproduces previous models which it found in the linguistic community it belongs to.

So, the dynamics' mechanisms imply the act of speaking, of real usage of language, in which the speaker makes their message by suing previous techniques stored in their linguistic science, so that they use the language they learnt to express their speaking freedom in the syntactic relationships' plan: „To speak always means to communicate. And, by communication, something turns into something common;

\footnotetext{
${ }^{20}$ Internal linguistic factors.

${ }^{21}$ External linguistic factors and extra-linguistic factors.

${ }^{22}$ Nicolai Hartmann, in Das Problem des geistigen Seins [Problema ființei spirituale] (p. 219), stated (as part of his philosophic system regarding the reality interdependence to the understanding ability) his ontological opinion about language: "The language's life is not different from the speakers' lives, is not situated, generally speaking, either next to it or above it."
} 
more exactly said, communication exists because those who speak have already had something in common, which appears in their speaking to each other" (E. Coseriu, apud Dewey and Heidegger).

The linguistic change has its origin in the dialogue: everything that goes away from the existing linguistic models represent an innovation ${ }^{23}$, and, when this innovation crosses the individual manifestation border, in becomes a social fact, so a linguistic innovation which has been adopted ${ }^{24}$ in the respective community, so that it stops from being an innovation due to the fact that it is no longer seen as such for the users of a certain linguistic system ${ }^{25}$. What at first appears as being an innovation individually, by adaption (namely by transforming that innovation into tradition), it becomes the expression of an inter-individual requirement manifested within the dialogue ${ }^{26}$. The linguistic change is essential for the languages' existence, because a language that does not change is permanent, so it forever fixes in its form, becoming only a system and ceasing to be a process ${ }^{27}$. An abstract language would result from here, even more than a simple cutout fixed in synchrony, which is actually a real cutout, at a certain time, from the concrete usage of a language. The language adapts itself to the speakers' needs of expression and goes on being a real language only when the adaptation process is uninterrupted, even when, frequently used, the adaptation means reusing some previous models, when that it is requested by the linguistic freedom and by the last finality of language-communication usage.

A clarification is required. The meanings the notion of dynamics get in this context diversify and, more precisely, become so complex it needs a special attention. We have already remarked that the language dynamics implies changing, a resulting modification of the innovation process, later of successive adaptation by which it occurs the transition from the speaker's individual linguistic culture to the group's (belonging to the same linguistic system) linguistic culture. But these changes can be generated with different results at its system balance level, in other words, they can have different consequences within the language economy: some of them can deposit themselves, so that the old forms are replaced by the new ones; some of them exist only because the language, through its mechanisms, while being concretely used in speaking, could decide upon the inutility of the respective change and could return to that change, at the same time returning to the previous form or, possibly, adopting a new form, a new one (either materially or ideally); others can exist in knowable and re-knowable cutouts from time or space without affecting the language in its entirely, neutral changes from its point of view ${ }^{28}$. The modifications (changes) can be neutral or can generate regress or progress.

In this regard, in Wald (2017) it is shown that: "Not everything that is new, as also progressive,

\footnotetext{
${ }^{23}$ With the possible options: alternation of a traditional model, selection between the possible models of previous linguistic accomplishment and which did not exceed the quality of a latent potency or hypothetic existence, loan, neglecting the superfluous distinctions in concrete use of language as a functional economy fact, etc.

${ }^{24}$ Changing in language represents the generalization of an innovation (speaking fact, so of language individual usage in a social context as part of the communication process), as a series of successive adoptions (turning an experience into a language fact, so becoming as well the starting point for other innovations in the process of continuous recovery of language).

${ }^{25}$ Both speakers and listeners, especially considering the fact that the linguistic system is a system of known possibilities, accepted and used (with a sufficient frequency) by the whole linguistic community.

${ }^{26}$ From this point of view, the language represents a collective creation, not in the sense in which all speakers bring the same innovation at the same time, but in the sense that every speaker innovates at a certain moment and these innovations are successively (or simultaneously) adopted by the other speakers belonging to the same linguistic community.

${ }^{27}$ I previously stated that in paradigmatic plan, the signs are invested with a virtual value in guiding the meaning process, regarding the signs' classes and categories they are grouped into, and in syntagmatic plan, the virtual variety is replaced by a concrete choice.

${ }^{28}$ Although it is difficult to accept the fact that some forms can appear, can exist or they can stop being without affecting the language in any way, as if they had never existed. The changes' neutrality has, at most, a theoretic character, because, in fact, linearity means degeneration to the language: "The syntactic structures and especially the terms become patterns where the euphemistic formulas pour, conventionalized metaphor, chichees, in their effort to create and impose a register oriented according to an ideology, then to extend it beyond its appearance. Because the language does not listen to the intellect anymore-in order to render its reason-, this kind of structures cannot offer a cognitive linguistic perspective, but they force an ideological construct whose movement can be, at most, linear (namely deteriorating, not progressive - authors' mention), by which the language replaces reality and thinking" (Gafton \& Gafton, 2016)
} 
the thesis post hoc ergo melius hoc does not always apply. This happens because there are modifications which do not affect the quality or uselessly complicates the system"; and on: "the progress notion cannot be substituted by that of evolution. During a phenomenon evolution, there are some modifications about its progress or regress, or others which do not change its quality in any way. The progress represents only a side of evolution, namely that which expresses the passing from a quality to a superior quality. As far as the language is concerned, it is obvious that we cannot interpret any modification as a sign of its progress or regress. In the same way we cannot consider that the languages keep their quality, during history, modifying themselves only in their unessential details."

With reference to theses changes, there is no justification for the semantic equality sign which is sometimes used between dynamics, change, progress, evolution. Only the first two of them (dynamics and change) make a pair in meaning, referring to the permanent mobility of linguistic systems, in the previous acceptance: the language can adapt to the speakers' need of expression and goes on living as a real language only if the adaptation process is an uninterrupted one, even in the situation, very common, when adaptation means resumption of some previous models, in so far as this is requested by linguistic freedom and is allowed by linguistic culture and by social-historic context; everything going away from the existing linguistic models represents innovation and, in so far as this innovation crosses the border of individual manifestation, it becomes a social fact, so a linguistic innovation which has been adopted by the respective community, so that it stops from being an innovation because it is no longer seen as such by the users of a certain linguistic system ${ }^{29}$. The dynamics means a change assuring the language progress or regress, both aspects, together with the neutral modifications, actually representing the language evolution, which depends on three factors: (a) increasing the units number at every language level, (b) qualitative transformation of their contents; and (c) strengthening every level and language systematic character.

Phonetically speaking (constitution of language phonologic inventory and phonemes' organizing in the system and its inner dynamics), an upward evolution, in the form of a spiral, can be recognized in the history of the words' sound complex in relation to their semantic contents, three stages being covered: (1) the stage of prevailing the motivated aspect of the sound form, (2) the stage of prevailing, on the contrary, the unmotivated aspect, (3) the stage of prevailing a relative, abstract and systematic motivation, where the motivation does not manifest to the extra linguistic reality, but to the system. The language gains, therefore, a superior state, defined by the capacity to create words which, keeping the ability to render an abstract contents, have the advantage of being easily understood and memorized, can be recreated by each speaker.

In the lexical field, the quantitative increase criterion (resulting from the double acquisition of some terms and from the loss of others-on the background of social and cultural transformations) is the weakest in setting the language progress degree. It gains weight only being associated to that of words' quality of their semantic force. From this point of view, the language acknowledges three positions, displayed also as a spiral, upward ${ }^{30}:(1)$ the undifferentiated general stage and vaguely (2) the precise notation and concrete stage, (3) the logic abstract stage.

The most complex issues are raised by the language morphology, these imposing a diachronic examination of many micro-systems related to the lexicon and syntax. But it also offers the weakest basis to speak about evolution, much less about progress in language. The approach difficulty is increased by the fact that, in itself, morphology represents the linguistic department which distinguishes, at the highest level, the language from each other, preventing from coming to unitary, standardizing conclusions. Contemporary related languages, having the same structural features and being considered at the same stage

\footnotetext{
${ }^{29}$ All these, despite some perspective situating both the changing and progress into a semantic pair: Karl Vossler, for example, considers that any innovation, later adopted by the speakers' community, automatically represents a progress.

30 "We could say that, due to the quantity of abstract words it consists of, the main fund reflects to a greater extent that the vocabulary overall, the development level of a community, as long as it does not indicate the number of abstract words a language has, but the type of abstract notions becoming current to the speakers" (Wald, 2017).
} 
of development, can display much distanced morphological features, even contrary. Although, overall we can admit the functioning of the same laws or general principles regarding the grammar change, independent of a certain language causality (optimization, for example, is an universal principle, common to all ages), the rhythm they act is distinct and, accordingly, differentiator. The upward director of language evolution is given by the tendency to abstract the contents regarding the morphological categories and their systematization.

The evolution tendencies in syntax, as well as in vocabulary, are easier to notice. As it is directly related to the forms of thinking, the syntax reflects its abstraction and complexity degree; thus, if we admit the existence of a progress regarding the thinking, we can admit, as a consequence, a progress regarding the syntax: "The increasing number of reports, their frequency and variety, imposes a more strict organization of language, which can be translated by sentence recitation and phase hypotax. From simple syntactic forms (topic, intonation), to abstract morphologic forms, as the one of flexion and of agreement resulting from here, and then to the specialized syntactic forms (prepositions, conjunctions), the syntax continuously records the evolution of thinking from concrete to abstract and, from here, to logical concrete-the superior stage of abstract, containing in itself, both the abstract and specificity" (Wald, 2017).

\section{Evolution in language}

To sum up, I will not choose the notion of progress. From the above offered information, we can clearly mention that the progress is only a side of evolution and it is extremely difficult to capture only the transformation from a quality to a superior quality ${ }^{31}$. The language changes in every meaning, the language is characterized by dynamics, and for this the language evolves. I will keep the term "dynamics", doubled by the one of "changing" and tightly related to "evolution", which is a feature of the reality a language belongs to, and which it tries to reveal ${ }^{32}$. The reality, within its progressive dimensions, is systematic, as previously stated, with functions resulting from its own constitution, related to the environment requests and following the universal principles. The language is natural creation, not a rational and logic construction, subjecting to the same universal principles, and the causes of its changing, both the linguistic ${ }^{33}$, and the extra-linguistic ${ }^{34}$, ones, faithfully reflect the direction of forces inducing the balancing tendencies and from whose action the changing results.

In Laland (2014) a clear distinction is made, although difficult to use it in practice, between causes and process. Thus, there are evolution causes, namely events generating the proper context for evolution, and an evolution process ${ }^{35}$, namely a dynamics which generates progress or regress or renewal, without modifications, in a new form of existence of a previous one.

A volcano erupts, generating extreme environmental conditions. Magma and hot gases pour out of the mountainside, and every living creatures that the lava stream crosses is demolished. Such eruptions are amongst the most destructive natural disasters known to science. Yet even here we see the evidence of evolutionary adaptation. For instance, an underwater volcano in

\footnotetext{
${ }^{31}$ The language degradation is a phenomenon which is not less natural than the progress regarding the languages' existence. Usually, the degradation or regress represents a balance phase for evolution, to which the language itself opposes the tendency of progress, of systematization, for example, and, thus, to which it comes back, in a restoring way, sooner or later. Much less often, the degradation process ends up with the language disappearance. The causes are varied: diverse nature accidents, improper historic conditions, pressure from other linguistic codes, reducing the social value of the respective language, disappearance of the speaking population, etc. (Chirilă \& Gafton, 2017).

${ }^{32}$ The language cannot be different from reality, the sequence cannot be different from the whole it belongs to, as well as the cell cannot function after other rules but those governing the organism which it is a part of.

${ }^{33}$ The erosive action of the phonetic laws, the system's dynamics, of its components and elements.

${ }^{34}$ The changes regarding the civilization, the culture, the mentality, the ages' discoveries and needs.

${ }^{35}$ We have to make the right and necessary correction between the generalized evolution and the niche evolution, the latter one meaning particular evolution ways, similar as long as they manifest themselves within contexts which are affined till identity.
} 
Guam has been erupting since 2004, and investigations of the marine life near it have revealed unusual varieties of fish, shrimp, crabs and limpets, including several newly identified species. These organisms thrive in hot water with strong chemicals, for instance, they possess anatomical adaptations that allow them to survivein extremely high sulphide concentrations. Seemingly, a history of volcanic eruption in the vicinity hascaused evolutionary change by leading to the natural selection of organisms able to tolerate or exploit the severe ecological statescreated. In common parlance we would feel entirely comfortable speaking of the volcano causing evolution, yet neither volcanoes, nor any other environmental change, are formally recognized as causes of evolutionary change in evolutionary biology textbooks.

This is not to suggest that evolutionary biologists fail to appreciate the causal link between environmental change and organismal change: of course they do. That relationship has been well-established since Darwin (1859). Yet the evolutionist would typically make a distinction between those processes that bring about changes in environmental conditions (amongst which they would include volcanic eruptions) and those processes that bring about lasting and heritable changes in organisms through modifying gene frequencies (where volcanoes do not show). For the evolutionary biologist, the real cause of those organismal adaptations for tolerance to extreme temperatures and chemical environments is natural selection. Other direct causes of evolution are also recognized, and include random genetic drift, gene flow and mutation. But volcanic eruptions, like all other phenomena that modify the circumstances in which organisms live, are not viewed as evolutionary causes: rather they are background conditions.

This distinction between a phenomenon that causes an evolutionary process to occur and a direct evolutionary cause or process itself, is a subtle but important one. Volcanic eruptions do not cause organismal change directly (if selections were impeded, for instance, though the absence of heritable variation, no organismal change would arise): rather, they create the conditions under which natural selection may (or may not) ensue. Note, this is a different description of causality from that found in common parlance, or even in other domains of science. If a nail is hit with a hammer we describe the hammer as the direct cause of the nail entering the wood. It would seem strange to describe the impact of the hammer as a background condition to the nail's momentum. To my knowledge, physicists see no need to distinguish, as categorically different, hammer-moving processes from wood-entering processes. Likewise, we would not be optimistic about the chances of the defendant in the dock receiving a 'not guilty' verdict if their defense was based on the argument that they did not cause the death of the victim that they shot-that was the bullet-, they only pulled the trigger. (Laland, 2014).

Within the same discussion meaning, Laland identifies some mutual causes ${ }^{36}$ : the environment offers the causes for the evolution starting the evolution process. Then, the already changed individual, changes the context in turn, because the general represents the sum of the individualities creating it, a context which, as it needs balance, thus again becomes an evolution cause. There are two stages of this process: successive and alternate: (1) from the context towards individual: the conformism ${ }^{37}$ is manifesting, because the individual has the tendency to follow the majority point of view, the more so as this majority have the authority attribute; (2) from the individual towards context: there is a moderate conflict ${ }^{38}$ to be found here, developing a stable evolution strategy which avoids major leaps, impossible to accomplish within the context. The evolution is to be done with small steps, what is stronger manifests itself for dominating the weaker, so that in the end it becomes, in itself, a contextual reality which, in its turn, will influence the individual by following the conformism principle.

\footnotetext{
${ }^{36}$ In this situation, reciprocity, consecutiveness, sociality, historicity manifest.

${ }^{37}$ The link between individual - conformism - social is theoretically and experimentally developed in Fessler et al. (2015).

${ }^{38}$ The idea of moderate conflict within the same species and its manifestation as an evolution stable strategy is developed in Maynard-Smith \& Price (1973).
} 
From the Darwinist perspective ${ }^{39}$, selection can generate evolution (continuous change), and through competition, the new form will eliminate its own parental forms, less perfect, and other less favored forms.

\section{Conclusions}

The language is a living organism, subjected to the universal evolution through variation and selection ${ }^{40}$. As a sound material that the thinking imperceptibly and with no finality transforms, under the unconscious action of the struggle for existence and of natural selection, the living organism-the languageis continuously evolving, due to a relative balance and a competition between a conservatory force and a revolutionary one. This aspect progressively encumbers the ages, in proportion to the amplitude of communication space and to its speed of movement. Although the balance between stability and variability is a natural one, it tends to torsion the organism beyond the bearable limits, the conservatory forces tending to keep the statu quo, the "revolutionary" one tending to impose the changing as a continuous reality, in an uncurbed dynamics, which does not allow natural sedimentation. As the natural variability is normally pretty high, the stabilizing factors are those which should dominate, their continuous action being necessary and assuring the system's natural evolution.

Moreover, the tendency to reestablish a balance which is affected by variability does not lead to coming back to previous balance, but to its restoration to other progressive level. The individual simple action generates variability, this pressure being managed by the stabilizing forces. But, because of pressures generated by the environment, by the increasing individuals' communities (as a result of the powerful action of civilization on them), the factors which stabilization ${ }^{41}$ is accomplished through get weakened more and more, not having the force of bringing and keeping, temporally, the balance. In this case, on the contrary, the "revolutionary" force starts acting continuously for itself, the only thing and fact offering and assuring real existence to any entity (stable balance) disappearing, with consequences on the organism's identity.

As a result of the progressive tension, the alternating game between stability and variability, between preservation and innovation, reflects the organism's inner needs in relation with itself and to the environment, as well as, being an adaptive one, the organism's external needs in relation with the context in which it exists and functions. Both for the organism and the complex structure it belongs to this game must be a reasonable one, tilting in favor of the first force, the language health and life resulting from the very reticent innovative force. The latter one is like the oxygen, assuring the necessary combustion for maintaining the existence and becoming, the former one is like carbon, assuring lasting, as such, of organic tissue which creates every being. Their natural tendency is selfish, but only to create a tension which is necessary to the existence in evolution, both of them being necessary and complementary, none of them having to be excluded, none of them having to prevail. Within this context, it is difficult to show if the solution for a balanced existence lies in the involvement of reason or to respond to natural trends.

\footnotetext{
${ }^{39}$ For the stage the Darwinism is nowadays, a pleading for natural sciences, for a good understanding of the world, we can find in Kellogg (2017): “The same species often remain constant for very different external conditions, both organic and anorganic. Darwin says: "For those considering the climate and life's physical conditions as being the most important elements of distribution, these facts must be surprising, because the climate, and the height or depth differ imperceptibly. But if we keep in mind that almost every species, even in the middle of its area, would increase in number if it weren't for the other competitive species, that almost all species are either preys or predators-shortly, if we consider that every organism is directly or indirectly related in an intimate way to the other organisms, we notice that the spread of inhabitants from any area does not exclusively depend on subtly changing physical conditions, but it mostly depends on other species' presence, which they live on or destroy, or which they compete with; and, as these species are already defined and do not pass ones into others through fine gradations, any species' spread, depending on other species' spread, will tend to be clearly delimitated." The selection follows the variation, and not variation follows selection.

${ }^{40}$ To be seen, for this approach, Darmesteter (2015). The following information represents the point of view stated in the Translator's note.

${ }^{41}$ Natural: civilization action, respect for tradition, children language supervision, tendency to a civilized language and standardization, natural-born common sense. Cultural: following the models offered by the sacred and literary texts, use of thinking and of quality people.
} 
Between language and thinking there is a tight relationship of inter-determination, the languages reflecting the people's mentalitary, spiritual and psychological habits. The fact that, sometimes, the old forms get new meanings, indicates the guiding, modeling influence the spirit has upon language, but also the form's resilient character, difficult to abandon. Exactly the way the biology is the history of differentiation by adapting to different environments, the same way the language subjects to transformism, whom it considers to be the language evolution law. Of course, the differences between languages reflect differences in thinking with profound implications generating critical differences culturally-spiritually and mentalitarily.

\section{Bibliography}

Benveniste, E. (1966). Problemes de linguistique generale, Gallimard, Paris.

Chirilă, A. \& Gafton, F. (2017). Recenzie la Lucia Wald, Progresul în limbă. Scurtă istorie a limbajului. Ediția a II-a, revăzută. Text îngrijit, notă asupra ediției și prefață de Petre Gheorghe Bârlea, Editura Universității „Alexandru Ioan Cuza”, Iași, 2017, 346 p., in "Diacronia", iss. 6, Sept. 30, A94, Crossref.

Coșeriu, E. (1997). Sincronie, diacronie și istorie (transl. N. Saramandu), Editura Enciclopedică, București.

Darmesteter, A. (2015). Viața cuvintelor studiată în semnificațiile lor (transl. Al. Gafton) Editura Universităţii „Alexandru Ioan Cuza", Iaşi.

Dessalles, J.-L. (2017). Către originile limbajului. O istorie naturală a vorbirii (transl. Al. Gafton), Editura Universității „Alexandru Ioan Cuza”, Iaşi.

Irimia, D. (1978). Curs de lingvistică generală, university manual for internal use.

Irimia, D. (2011). Curs de lingvistică generală (ed. I. Milică \& I. Moisuc), $3^{\text {rd }}$ ed., Editura Universităţii „Alexandru Ioan Cuza”, Iași.

Fessler, D. M.T., Barrett, H.C., Kanovsky, M., Stich, S., Holbrook, C., Henrich, J., Bolyanatz, A.H., Gervais, M.M., Gurven, M., Kushnick, G., Pisor, A.C., von Rueden, C. \& Laurence, S. (2015). Moral parochialism and contextual contingency across seven societies, in "Proceedings. Biological Sciences", vol. 282, 20150907, Crossref.

Gafton, Al. \& Gafton, E. (2016). Reality, Science, Method, in "GIDNI", IV, p. 9-24.

Graur, Al., Stati, S. \& Wald, L. (1971). Tratat de lingvistică generală, Editura Academiei R.S.R., București.

Kellogg, V.L. (2017). Darwinismul astăzi (transl. Al. Gafton, A. Chirilă), Casa Editorială Demiurg, Iaşi.

Laland, K.N. (2014). On evolutionary causes and evolutionary processes, in "Behavioural Processes", vol. 117, p. 97-104, Crossref. Maynard-Smith, J. \& Price, G. R. (1973). The logic of animal conflict, in "Nature", vol. 246, p. 15-18, Crossref.

Saussure, F. de (1998). Curs de lingvistică genarală (transl. I. Izverna Tarabac), Editura Polirom, Iași.

Wald, L. (2017). Progresul in limbă. Scurtă istorie a limbajului, revised $2^{\text {nd }}$ ed., Editura Universității „Alexandru Ioan Cuza”, Iași. 